\title{
O NEORRETRIBUCIONISMO EM MATÉRIA PUNITIVA
}

\author{
NEO-RETRIBUTIONISM IN PUNITIVE MATTERS
}

\author{
EL NEORRETRIBUCIONISMO EN MATERIA PUNITIVA
}

\section{Augusto Jobim do Amaral'}

\section{Ricardo Jacobsen Gloeckner²}

Licença CC BY:

Artigo distribuído sob

os termos Creative

Commons, permite

uso e distribuição

irrestrita em qualquer

meio desde que o

autor credite a fonte

original.

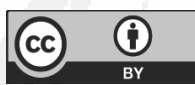

\begin{abstract}
Resumo: O artigo explora as bases do neorretribucionismo e as suas relações com as teorias denominadas relativas ou utilitárias da pena. Como hipótese de trabalho, partiu-se do pressuposto de que a grande maioria das teorias chamadas de neorretribucionistas ampara-se largamente em elementos preventivos, tratando de integrá-los por meio de posturas ecléticas. Como método exploratório e a fim de testar a hipótese, tratou-se de examinar em particular as obras de dois autores, Andrew von Hirsh, com a sua teoria do "justo merecimento", e a releitura da pena como retribuição em José de Faria Costa.
\end{abstract}

Palavras-chave: teorias da pena; neorretribucionismo; prevenção; castigo.

1 * Professor do Programa de Pós-Graduação em Ciências Criminais (mestrado e doutorado) da PUCRS; Doutor em Altos Estudos Contemporâneos pela Universidade de Coimbra (Portugal) e Doutor em Ciências Criminais pela PUCRS.E-mail: guto_jobim@hotmail.com.

2 ** Professor do Programa de Pós-Graduação em Ciências Criminais (mestrado e doutorado) da PUCRS; Doutor em Direito pela UFPR. E-mail: ricardogloeckner@hotmail.com. 
Novos Estudos Jurídicos

\begin{abstract}
: this article explores the connections between neo-retributivism and its relations with socalled relative or utilitarianist theories. As a hypothesis of this work, we assume that the large majority of the neo-retributivists theories are largely based on preventive elements, seeking to integrate them through eclectic postures. Using the exploratory method, in order to test the hypothesis, we examined the works of two authors: Andrew von Hirsch and José de Faria Costa.
\end{abstract}

Key-Words: penalty theory; neo-retributionism; prevention; punishment.

Resumen: El artículo explora las bases del neorretribucionismo y sus relaciones con las teorías denominadas relativas o utilitarias de pena. Como hipótesis de trabajo, se partió del presupuesto de que la gran mayoría de las teorías llamadas de neorretribucionistas se ampara largamente en elementos preventivos, tratando de integrarlos por medio de posturas ecléticas. Como método exploratorio y a fin de verificar la hipótesis, se trató de examinar en particular las obras de dos autores, Andrew von Hirsh, con su teoría del "justo merecimiento", y la relectura de pena como retribución en José de Faria Costa.

Palabras-clave: teorías de pena; neorretribucionismo; prevención; castigo.

\title{
INTRODUÇÃO
}

Induvidoso assinalar que, na transição da década de 70 para a de 80, houve um giro discursivo capaz de, a partir da detecção dos mais distintos gravames que percorriam as entranhas das teorias justificacionistas da pena, fossem eleitas outras de mais fácil apreensão - rectius: articulação como narrativa autolegitimadora. Com efeito, a perda de legitimidade - vislumbrada desde aspectos que se poderiam dizer, não sem grandes impropriedades, como "metaéticos" uma espécie de reorganização nos distintos discursivos penalógicos.

Parte dos discursos que gravitavam ao redor do utilitarismo clássico, interpretado a partir de ideais ressocializadores - paragem obrigatória no largo campo do Estado de Bem-Estar -, entra em colapso quando as condições que subjazem ao mais bem-acabado panorama político - qual seja, a consolidação do neoliberalismo, para além de um modelo econômico, mas como modo de vida ${ }^{4}$ - passam a ditar uma nova razão-mundo. Portanto, isto não haveria de deixar indenes as estruturas que comportavam e articulavam os discursos penológicos. Assim, a partir de uma nova orientação, as bases do Welfare State

3 Cf. ZAFFARONI, Eugenio Raúl. Em busca das penas perdidas: a perda de legitimidade do sistema penal. Rio de Janeiro: Revan, 1991.

4 Cf. DARDOT, Pierre; LAVAL, Christian. A Nova Razão do Mundo: ensaio sobre a sociedade neoliberal. São Paulo: Boitempo, 2016. 
foram minadas por sedimentos que advinham de áreas outras. Mesmo quando ainda se reafirmava o discurso justificacionista, ele se apresentara dentro de um novo enquadramento, aquele da dita "incapacitação seletiva" (por alguns, denominada como prevenção especial negativa).

Tudo ainda posto dentro de um quadro político-criminal mais geral que tinha, por um lado, o retorno ao funcionalismo nas ciências sociais e na criminologia e, por outro, o amparado numa reorganização do direito penal preocupado com o fenômeno da criminalidade transnacional e transfronteiriça, que culminará, anos mais tarde, com os discursos em torno do terrorismo e de seu financiamento como as principais figuras de política criminal contemporâneas. Todavia, como referido, abria-se um flanco para, a partir do decreto de falência do discurso clássico prevencionista produzido no seio do Estado de Bem-Estar, florescesse uma perspectiva de resgate do idealismo filosófico, temperado por um pessimismo imobilizante. A descrença na capacidade da pena em produzir qualquer utilidade social tornou-se, por assim dizer, um significante reorganizador. Todas as correntes que apostavam neste cenário de incapacidade da pena de atingir determinadas finalidades foram sobrepostas desde aquilo que se poderia denominar - na falta de uma melhor sintonia fina e de melhor ajuste relativamente aos problemas estruturantes que alinham tais horizontes discursivos - como neorretribucionismo.

Desde os mais distintos matizes, em especial pelo sentimento de que a dogmática deveria se ocupar, num trato contínuo interno, de plataformas político-criminais ${ }^{5}$, ou ainda, de que as justificativas para a atuação do direito penal deveriam abdicar da centralização de sua legitimidade em bens concretos ou antropológicos ${ }^{6}$, o neorretribucionismo foi capaz de ganhar inegável espaço no campo da dogmática penal e da criminologia.

O mais importante é que o novo modelo não aparecera somente como um discurso simplificado de abandono de finalidades reais ou imediatas, em detrimento de suas funções latentes (denúncia já feita pela criminologia radical

5 ROXIN, Claus. Política Criminal e Sistema Jurídico-Penal. Rio de Janeiro: Renovar, 2002.

6 Como se pode encontrar em AMELUNG, Knut. El Concepto "Bien Jurídico" en la Teoría de la Protección de Biens Jurídicos. In: HEFENDEHL, Roland. La Teoría del Bien Jurídico ¿Fundamento y Legitimación del Derecho Penal o Juego Abalorios Dogmático? Madrid: Marcial Pons, 2007; JAKOBS, Gunther. Sociedad, Norma, Persona: en una teoría de un derecho penal funcional. Bogotá: Universidad Externado de Colombia, 1998 e LESCH, Heiko H.

La Función de la Pena. Madrid: Dykinson, 1999. 
ainda na década de 70$)^{7}$, houve câmbios profundos na própria concepção da prisão, no retorno de sanções ainda mais graves (retomada das penas de morte, ampliação das hipóteses de prisão perpétua são alguns exemplos). E isso sem qualquer reorganização dos denominados substitutivos penais, o que implicou (e implica) na articulação ostensiva de camadas de mecanismos disciplinares, atuando para além da plataforma da prisão. ${ }^{8}$

Além do aparecimento do neorretribucionismo concernente à justificativa oferecida para a pena, contemporaneamente não são raras as tentativas de conciliação entre concepções relativas (melhor dizendo, prevencionistas, de caráter geral e especial) com as "absolutas", ou seja, com aquelas denominadas retributivas. Assim, teorias como a "prevenção-integração", "prevenção geral positiva" são construtos sem sombra de dúvidas artificiais, advindos do intento de se atribuir efeitos preventivos à retribuição. ${ }^{9}$

Portanto, em nível de hipótese da qual se parte este estudo, serão enfrentadas duas questões de valência fundamental: o denominado neorretribucionismo trata de integrar efeitos preventivos na pena, seja de forma clara ou velada. Como no espaço restrito deste artigo não há espaço para se analisar uma a uma as diversas concepções da pena que se poderiam remeter à hipótese examinada, tratar-se-á de dois autores que podem servir como ponto de análise para a discussão em torno do fenômeno: o primeiro deles, Andrew von Hirsch; o segundo, José de Faria Costa.

\section{ANDREW VON HIRSCH: A PENA COMO JUSTO MERECIMENTO}

Andrewvon Hirsch pode ser interpretado como um dos mais refinados autores no campo da teoria do justo merecimento da pena (just deserts). Sua principal obra (ainda que tenha sido ao longo do tempo objeto de sistemáticas modificações em alguns de seus pontos essenciais) pode ser tida como representativa de um estilo de pensar que procurou apresentar uma fundamentação para a pena a partir do marco da proporcionalidade. Contextualmente, sua obra Doing Justice: the choice of punishments consiste na tentativa de estabelecer um marco referencial para a

7 Cf. TAYLOR, Ian; WALTON, Paul; YOUNG, Jock. The new criminology: for a social theory of deviance. London: Routledge \& Kegan Paul Ltda., 1973.

8 Cf. ROSA, Alexandre Morais da; AMARAL, Augusto Jobim do. Cultura da Punição: a ostentação do horror. 4.ed. Florianópolis: Empório do Direito, 2017.

9 BARATTA, Alessandro. Integración-Prevención: Una "Nueva" Fundamentación de la Pena Dentro de la Teoría Sistémica. In: Revista Doctrina Penal, año 8, n² 29, 1985, Buenos Aires, Argentina, pp. 9-26. 
pena, especialmente nos Estados Unidos ${ }^{10}$.

Evidentemente, há que se traçar alguns aportes contextuais em torno da obra, porque ela, com efeito, é produto da discussão então travada no ambiente americano. Até o final dos anos 70, seria possível afirmar que a ideologia penalógica predominante era a de reabilitação. Várias críticas eram endereçadas a esta ideologia, especialmente àquelas contra as sentenças indeterminadas (indeterminate sentencing), que reuniram as mais distintas perspectivas criminológicas. A teoria do justo merecimento, portanto, pertence a este momento. Como resultado das intensas críticas, sucede um movimento que advogava em prol das sentenças determinadas (determinate sentencing). O Estado pioneiro na formulação de diretivas absolutamente diversas no procedimento de sentenciamento foi o de Minnesota, que em 1980 elaborou guias penais (sentencing guidelines). Tratou-se de um movimento simetricamente oposto àquele da indeterminação das sentenças: procurou estabelecer uma graduação das penas correspondentes a cada tipo delitivo. Posteriormente, a técnica se espalhou pelos Estados Unidos, até a sua recepção pela justiça federal.

No contexto da formulação das bases da teoria do justo merecimento, também não se pode esquecer de um movimento que reivindicava um mínimo de pena (minimum mandatory sentences), que estaria colado a outro, exigindo a abolição do livramento condicional: o truth in sentencing. No sentido da retomada da punição capital e da prisão perpétua, aparece a defesa da incapacitação (prevenção especial negativa) como uma finalidade da pena. Em 1994, como exemplo desta dinâmica, a noção de three strikes and you 're out (no terceiro crime, prisão perpétua) acabou sendo adotada por alguns estados norte-americanos.

Portanto, a teoria do justo merecimento pertence a este contexto. A teoria do merecimento identifica como principal elemento a proporcionalidade das sanções. Segundo Hirsch, a sua força reside, primeiramente, na sua plausibilidade ética. Em segundo lugar, concede aos juízes uma orientação, o que outras teorias dificilmente conseguem ${ }^{11}$.

A hipótese da qual parte o autor é a de que a proporcionalidade surge como

10 HIRSCH, Andrew von. Doing Justice: the choice of punishments. New York: Hill \& Wang, 1976.

11 HIRSCH, Andrew von. Censurar y Castigar. Madrid: Trotta, 1998, p. 23. 
uma exigência de justiça: as sanções devem ser proporcionalmente severas à gravidade das infrações cometidas ${ }^{12}$. Para tanto, as justificativas do castigo devem se basear na censura ou na reprovabilidade da conduta, ou seja, no dano causado pelo infrator ${ }^{13}$. Segundo Hirsch, seria mais fácil vincular a proporcionalidade à reprovabilidade da conduta; já que o castigo indica censura, seria lógico que o seu quantum tenha relação com a prática da conduta criminosa ${ }^{14}$.

Como destaca Strawson, a capacidade de uma pessoa responder pelo mal por meio da reprovabilidade de sua conduta está assentada na moralidade, que toma as pessoas como responsáveis pelas suas ações ${ }^{15}$. Contudo, inevitável o questionamento de, em sendo o castigo aplicação de sofrimento, como justificálo unicamente por meio da reprovabilidade? Segundo Hirsch, deve haver uma "explicação dualista do castigo" ${ }^{16}$. Segundo ele, o direito penal atende a duas funções: a) ameaça com sanções desagradáveis, visando que as pessoas deixem de praticar tais condutas; b) reprova tais condutas por meio da pena. Assim, o direito penal, além de oferecer razões "prudenciais" para a desistência da ação, ofereceria "razões morais". Tem-se, portanto, segundo a teoria do merecimento de Hirsch, a combinação entre reprovação e prevenção.

A função preventiva, para Hirsch, consiste em oferecer razões prudenciais que complementariam as razões normativas encontradas na reprovação penal. As normas penais, de forma implícita, advertem o agente de que a sua conduta não é aceitável, enviando ao agente razões morais para desistir da conduta. Primeiramente, sem abdicar do fundo racionalista de sua teoria, Hirsch afirma que as pessoas, como agentes morais, são capazes de compreender a mensagem enviada pela norma penal: de que a conduta ali prevista é merecedora de sanção, não devendo ser, então, praticada. A prevenção ingressaria no plano da concepção de pena do autor no momento em que considera os agentes, mesmo capazes de compreender a norma penal e a mensagem implícita contida falíveis, podendo ceder à tentação de violar a norma penal. A função da pena, portanto,

12 HIRSCH, Andrew von. Censurar y Castigar, p. 31.

13 WASSERSTROM, Richard A. Punishment. In: Philosophy and Social Issues: five studies. South Bend: Notre Dame University Press, 1980.

14 HIRSCH, Andrew von. Censurar y Castigar, p. 35.

15 STRAWSON, Peter. F. Freedom and Resentment. In: Freedom and Resentment and Other Essays. London: Routledge, 2008.

16 HIRSCH, Andrew von. Past or Future Crimes: deservedness and dangerousness in the sentencing criminals. New Brunswick: Rutgers University Press, 1987. 


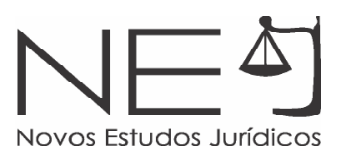

de forma preventiva, é desincentivar a conduta e oferecer uma razão prudencial para desistir da ação ${ }^{17}$.

O que Hirsch afasta de pronto é uma concepção da pena que atenderia a funções exclusivamente preventivas, isto é, desprovidas de quaisquer elementos baseados na reprovabilidade da conduta. Afirma o autor que a prevenção, ausente a censura, equivale a "controle de tigres" ${ }_{18}$. Assim, mesmo que perspective uma composição entre prevenção e reprovação, afirmará o autor que esta última contará com a primazia, o que lhe permite afirmar que a prevenção somente pode adquirir contornos específicos inserida dentro do âmbito da reprovabilidade ${ }^{19}$.

Já no que diz respeito à proporcionalidade, então, aparecem três estágios: a) as sanções estatais contra a conduta delitiva devem adotar a forma punitiva, o que implica em dizer que devem possuir natureza de censura e reprovabilidade; b) a severidade da pena expressa a gravidade da censura; e c) as sanções punitivas deveriam ser organizadas de acordo com a gravidade da conduta (isto é, de acordo com o nível de reprovação da conduta) ${ }^{20}$.

A proporcionalidade, para Hirsch, permite que se mantenham tanto uma base de reprovação quanto de prevenção relativas à estrutura do delito. Assim, estaria a proporcionalidade de acordo com a "explicação dualista do castigo". Dividirá o autor a proporcionalidade em duas dimensões: a ordinal e a cardinal. A proporcionalidade ordinal se refere à comparação entre as penas, fundamentando-se em uma concepção de reprovação do castigo. Para tanto, deve a proporcionalidade ordinal atender a três exigências: a) paridade; b) distribuição de uma graduação de acordo com um ranking do crime mais grave ao menos grave; e c) criação de espaçamentos entre as penas aplicadas. Portanto, quando Hirsch estabelece a proporcionalidade ordinal, tem em mente uma proporcionalidade relativa, que deve obedecer aos três itens anteriormente descritos. Contudo, não é só. A proporcionalidade cardinal ou ainda, não relativa, diz respeito aos limites intrínsecos, ou seja, aos limites imanentes à proporcionalidade de um castigo. Limites não ultrapassáveis, que impõem uma barreira a qualquer castigo ${ }^{21}$.

17 HIRSCH, Andrew von. Censurar y Castigar, p. 39-40.

18 HIRSCH, Andrew von. Censurar y Castigar, p. 40.

19 HIRSCH, Andrew von. Censurar y Castigar, p. 41.

$20 \mathrm{HIRSCH}$, Andrew von. Censurar y Castigar, p. 42.

21 HIRSCH, Andrew von. Censurar y Castigar, pp. 45-46. 
Como se poderá perceber claramente, a "explicação dualista do castigo" consiste em uma tentativa de conciliar as chamadas teorias "relativas" com as teorias "absolutas". A questão fundamental, a saber, é se tal relação consegue de fato manter a primazia entre reprovação e prevenção. E, para além disso, deverá se atender se o que o autor denomina como retribuição não é, em realidade, uma justificativa suficiente para que a reprovabilidade não nasça de uma relação já demarcada pela prevenção.

\subsection{REPROVAÇÃO E PREVENÇÃO: RAZÕES MORAIS E PRUDENCIAIS COMO FUNDAMENTO DO CASTIGO?}

Da rápida apresentação sobre a fundamentação do castigo em Hirsch, passa-se à análise valorativa de seu contributo. Não há dúvidas de que a teoria do justo merecimento se inscreve na crise do utilitarismo clássico, aproveitandose de toda a crise que recaiu sobre as concepções relativas da penalidade.

O autor, ao rever a sua própria teoria (neste ponto, Hirsch avança relativamente da sua obra seminal) e estabelecer uma dupla fundamentação do castigo, pode ser inscrito naquele grupo de teorias neorretribucionistas ecléticas, isto é, que não abandonam completamente o núcleo prevencionista das justificativas do direito penal. Melhor dizendo, sua teoria poderia ser qualificada de "mista", à medida que trata de conciliar discursos que sempre se encontraram em polos antagônicos.

Contudo, mesmo que o autor defenda a primazia dos pontos de vista de reprovação e eleve a censura ao patamar de delimitador da própria prevenção, a rigor, tem-se um modelo invertido. A noção de reprovação acaba ela própria se colocando, quando muito, como um elemento de restrição, de limitação de políticas criminais claramente preventivas. O argumento de que a prevenção, por si só, não admite que o ser humano seja interpretado como agente moral (capacidade de autodeterminação) é em vários pontos dúbia.

A começar pela própria escala de crimes. A prisão, propõe o autor, deve estar limitada para os crimes mais graves ${ }^{22}$. Afirma o autor: para os crimes violentos e os 22 HIRSCH, Andrew von. Doing Justice: the choice of punishments, p. 16. 
casos mais graves de crimes de colarinho branco. Afirma que, para os crimes de colarinho branco, a pena máxima deveria ser de três anos de reclusão, assim como os demais crimes violentos. Excepcionalmente, o homicídio teria pena mais larga (cinco anos de reclusão, exceção feita aos homicídios mais atrozes). Entretanto, parte da discussão em torno da sanção, neste ponto, tem como pano de fundo a compreensão de uma sociedade democrática que, para Hirsch, é aquela cujas instituições básicas e elementares se desenvolvem tendo como modelo o "cidadão responsável". E isto teria validade inclusive para o castigo.

Para tanto, o castigo, indiscutivelmente, lida com ocasiões em que um sujeito agiu mal, devendo ser a resposta dirigida a um adulto racional e autônomo. Os infratores, portanto, devem ser vistos como capazes de compreender a mensagem articulada implicitamente na norma penal. Neste ponto, então, o potencial criminoso é considerado desde o ponto de vista da economia como alguém capaz de autogoverno (seria possível inclusive descer às provocações de Foucault quando examina o cuidado de siz ou, ainda, consoante Dardot e Laval, o criminoso como um empresário de si). A direção empregada pelas teorias preventivas estaria, de acordo com o autor, em uma visão que concebe o criminoso como agente perturbador da ordem, devendo tais atos agressivos serem prevenidos da forma mais eficiente possível ${ }^{24}$.

Não é preciso ir muito adiante para se constatar que todo o aporte sobre a reprovação, baseada na "mensagem" proibitiva que acompanha a norma penal, está assentada nas mesmas premissas das quais parte a denominada prevenção geral positiva. Duas premissas aparecem como fundamentais na construção do modelo de Hirsch: a) de que todo ser humano é um ser racional e livre (autônomo), o que implica, tanto para bem como para mal, cair nas mesmas trampas idealistas hegelianas ou neohegelianas; b) apostando todas as suas fichas na capacidade intelectiva de um sujeito racional e autodeterminado, não apenas se parte de um modelo fantasmático de sociedade, como também a ameaça penal - e a censura se encontrariam inseridas no plano de validade da norma. Não é difícil, portanto, reconciliar este discurso que parte de um recorte moral de cariz economicista,

23 FOUCAULT, Michel. História da Sexualidade III: o cuidado de si. 8. ed. Rio de Janeiro: Graal, 1985.

$24 \mathrm{HIRSCH}$, Andrew von. Past or Future Crimes: deservedness and dangerousness in the sentencing criminals, p. $9-11$. 
de um sujeito que mede as suas ações de acordo com uma vontade sempre disponível para atender aos ditames da consciência como, agregado a isso, com o pano de fundo de um funcionalismo que aposta na norma penal para proteger a "identidade normativa" de determinada sociedade. Neste ponto, a razão moral oferecida pelo castigo corresponde a um retorno hegeliano de identificar o agente criminoso como ser racional25. Há uma coincidência muito clara entre a denominada prevenção geral positiva (restauração da validade da norma abalada pela prática criminosa) e o neorretribucionismo, independentemente do acento ideológico de que seja portador.

Segundo o modelo liberal-economicista de Hirsch, a reprovação, que outorga uma razão moral à pena, deve ser proporcional ao castigo. Mas, quando a capacidade de autodeterminação relativamente à compreensão do ilícito falha, uma razão "prudencial" atuaria como uma espécie de suplemento a emprestar reforço normativo à norma penal. O jogo parece mudar de posição quanto se atenta para os fatores delimitadores atribuídos à proporcionalidade. Com efeito, o caráter retributivo da pena é insuscetível de ser comprovado empiricamente. Como efeito do restabelecimento da validade da norma abalada, que mede em outros termos a adequação do comportamento ao injusto contido e expresso pela norma penal, evidentemente que não se poderia estabelecer uma proporcionalidade neste campo, a não ser aquela denominada por Hirsch como "ordinal". Ora, para tanto, recorre-se à teoria dos limites imanentes e, então, a retribuição somente adquire sentido negativamente: serve ela apenas como um guia contra uma punição desproporcional. Mesmo nesta hipótese, a proporcionalidade acaba servindo como um mero instrumento de mensuração do desproporcional, o que já indicaria certo grau utilitário de segundo grau. Se a proporcionalidade serve apenas como um elemento de valoração negativa, seria de extrema dificuldade criar as guias de escalonamento das penas, posto que, como visto, a proporcionalidade ordinal ou relativa só adquire sentido uma vez formulado um juízo prévio que permita elaborar-se a pena mais grave e a mais

25 "A pena que afeta o criminoso não é apenas justa em si; justa que é, é também o ser em si da vontade do criminoso, uma maneira de a sua liberdade existir, o seu direito. Necessário ainda acrescentar que, com relação ao próprio criminoso, constitui ela um direito: está já implicada na sua vontade existente, no seu ato. Este ato, porque vem de um ser de razão, implica na universalidade que por si mesmo o criminoso reconheceu e à qual se deve sujeitar como ao seu próprio direito". HEGEL, G. W. F. Princípios de Filosofia do Direito. São Paulo: Ícone, 1997, p. 105. 
branda admissível. Todavia, a proporcionalidade cardinal - absoluta - apenas mede a ultrapassagem para além ou aquém dadas pela própria gravidade do delito cometido, o que implica, inexoravelmente, determinado nível de arbitrariedade nestes limites.

A bem ver, parece que a relação de primazia na determinação da relação entre prevenção e reprovação se encontra em uma posição invertida. Seria justamente o caráter supletivo das razões prudenciais a autorizar a formulação da própria compreensão do homem "autônomo". As "razões prudenciais", aditivas relativamente às razões morais incrustradas nos comandos inerentes ao programa penal contido na norma, seriam a própria razão de existência da norma. Em última instância, a crença de que o conteúdo do injusto é apreendido pelo homem, que necessita, porém, de uma barreira contra a tentação de descumprir a norma, coloca toda a razão moral como que protegida pela razão prudencial. A "explicação dualista do castigo" se encarrega de duplamente posicionar a prevenção como núcleo irredutível do sistema penal: a) num primeiro momento, ao explorar a capacidade de entendimento do homem, eventual violação à norma penal estará carregada de sentido correcional, no sentido de que o comportamento contrário à norma é injusto. A dimensão de significado da conduta não pode ser neste ponto desprezado; b) por outro lado, ao estabelecer uma "reserva normativa" que pauta comportamentos potencialmente falhos, não há dúvida de que a prevenção acaba se constituindo como a principal, garantia de que os mandamentos contidos na norma serão obedecidos.

Neste momento, a proporcionalidade não serve mais do que uma ferramenta corretiva relativa unicamente à plataforma de política criminal concernente aos imperativos prevencionistas. A noção de proporcionalidade, aplicada exclusivamente por meio da remissão à fórmula gravidade do crime $x$ necessidade de reprovação implica exclusivamente num modelo negativista de mensuração de punições intoleráveis (limites imanentes). Será justamente na sua relação com a prevenção que a proporcionalidade poderá perfazer qualquer medida mais eficaz na contenção de eventuais exageros ou estabelecimento de penas desproporcionais. Sempre como medida corretiva e delimitadora. Porém, já neste ponto, a proporcionalidade se torna numa ferramenta de correição 
político-criminal, sub-rogando-se no papel de elemento intrínseco à prevenção (e não à reprovação).

Como é possível se observar, há neste ponto uma inquestionável mudança de orientação relativamente às noções de prevenção e reprovação embutidas na teoria do justo merecimento, com a subordinação da reprovação à prevenção.

\section{A LEGITIMIDADE PREDISPOSTA COMO FUNDAMENTO DA PENA}

Ubi societas, ibi poena? Será a história do próprio convívio humano a mesma da imposição da pena? Na hipótese de aderir nesta direção, mesmo assim já aí estaria incluída sua legitimidade? O sentido de interrogar certas questões que poderiam defluir daí já se coloca diante da questão fulcral do pensamento de José de Faria Costa: a naturalização do poder punitivo, como se fosse um acontecimento a-histórico e não, ao menos, uma construção política oriunda do medievo ocidental colonial posta como modelo planetário de verticalização e controle social. ${ }^{26}$ Concebe Faria Costa, a rigor, o viver comunitário desde alguma estrutura fundada numa norma de proibição, num Interdito - de valor matricial inclusive para dar sentido à relação de "cuidado-de-perigo", segundo o professor lusitano ${ }^{27}$. Mesmo se assim se admitisse estritamente a ancoragem do animal político sobre tal Lei, diante dos debates que se alargam ao menos desde Freud ${ }^{28}$

26 ZAFFARONI, Eugenio Raúl. A Questão Criminal. Tradução Sérgio Lamarão. 1. ed. Rio de Janeiro: Revan, 2013, pp. 18 ss.

27 FARIA COSTA, José Francisco de. 0 perigo em direito penal. Coimbra: Coimbra Editora, 2000, pp. 423-454.

28 É por meio do mito de Édipo, descrito por Freud (FREUD, Sigmund. La Interpretación de los Sueños. In: Obras Completas. Tomo I. Buenos Aires: El Ateneo, 2005, pp. 506-507), do crime praticado contra o Pai da Horda, que ele reconstrói o advento social. O Totem - antepassado comum ao grupo - constitui-se objeto de Tabu (FREUD, Sigmund. Totem y Tabu. In: Obras Completas. Tomo II. Buenos Aires: El Ateneo, 2005, pp. 1748 e 1758). Este significava as interdições e proibições, ou seja, o que há por detrás é um desejo limitado: "dado que el tabu se manifiesta principalmente por prohibiciones, podríamos suponer, sin necessidad de buscar confirmación alguna en la investigación de las neurosis, que tenía su base en deseos positivos. No vemos, en efecto, que necesidad habría de prohibir lo que nadie desea realizar; aquello que se hallan severamente prohibido tiene que ser objeto de un deseo." (FREUD, Sigmund. Totem y Tabu, p. 1791). O Tabu como proibição primeva não afasta, assim, o desejo de violá-lo que permanece no inconsciente. E o fato de a violação de um Tabu poder ser expiada por uma renúncia mostra que esta renúncia se acha na base da obediência ao Tabu. (FREUD, Sigmund. Totem y Tabu, p. 1769). E será mediante o crime perpetrado contra o Pai terrível da Horda que os irmãos se reconhecerão definitivamente frente à fascinação mortífera do onipotente: "o pai, enquanto tal, não existe a não ser morto realmente ou simbolicamente; que nos leva a uma noção fundamental: o pai não existe a não ser como pai 'mítico'. (...) Mas o pai, em sua função mítica, é aquele que provoca reverência, terror e amor ao mesmo tempo, o pai é aquele que sufoca, castra e que deve então ser morto ou, no mínimo vencido; ele é, além disso, o portador e depositário das proibições. Seu assassinato é acompanhado de culpa e veneração. Não existe mais o pai real. O pai é sempre um pai morto, e o pai morto é sempre um pai mítico." (ENRIQUEZ, Eugène. Da Horda 
a Levi-Strauss (sem esquecer interlocutores privilegiados como Lacan), este esforço de base antropológica parece apenas ter por objetivo ser visto como espelho da sua completa simetria com as proibições advindas do direito penal.

A não ser se que possa pressupor entidades criminosas e ações a elas correspondentes de maneira atemporal, ou apenas reatualizáveis historicamente, quer dizer, apenas assim não haveria maneira de supor a radical diferencialidade trazida pela Kultur como traço em nada conatural ao direito penal (entendido como exercício de poder punitivo). Talvez fosse algo semelhante a aceitar - de maneira pouco frouxa - que qualquer conjunto de normas de proibição, tal como o direito penal, carregasse também o mesmo sinal de implicação conatural ao nosso modo de ser. Seria o mesmo que entender que a Norma - que se dá no sentido de fundação e exatamente carrega o Mito - pudesse deixar de ser exatamente o que permite que o simbólico se dê - desmetaforização do mito, pois se acede à linguagem propriamente por "apenas" poder dizê-lo. Se o Mito pode ser descrito como aquilo que, em sendo, não pode ser dito, pois se trata de uma outra cena, talvez acoplar a ideia de que o crime em si, como entidade políticojurídica assim entendida, seja o mesmo que o tabu, vê-lo como apresentação da proteção desta Norma, seria deixar de discernir inescusavelmente o direito da Lei, coisificá-la.

Trata-se de simular uma confusão entre a primeira interdição que se apresenta e a estrutura, se assim se quiser, do próprio inconsciente do indivíduo (eis que é a partir dela que é inserido na linguagem, tendo acesso ao simbólico), com os significantes desprendidos por esta cadeia inaugurada, será coincidir, de forma equívoca, a assimetria radical, enfim, entre a Lei do Outro e a lei penal. ${ }^{22} \mathrm{D}$ e $\mathrm{s}$ t a

ao Estado: Psicanálise do vínculo social. Rio de Janeiro: Jorge Zahar, 1990, p. 31). O banquete servido e o sangue derramado, a culpa pelo assassinato há de retornar. Abandonado o estado de natureza, erigida estará a civilização, e seu "mal-estar", pela edificação do Pai simbólico decorrente da culpa. Mito necessário, segundo Freud, que se inscreve na partida de toda a história - com o amor na origem da consciência e a inevitabilidade do sentimento de culpa -, instaura a dimensão simbólica editando a civilização (FREUD, Sigmund. El Malestar en la Cultura. In: Obras Completas. Tomo III. Buenos Aires: El Ateneo, 2005, pp. 3017-3067).

29 Talvez se aqui se pudesse entrar nas linhas mestras de tal pensamento, deveria ser dito, quanto aos registros Simbólico-Imaginário-Real (ver LACAN, Jacques. O Simbólico, o imaginário e o real. In: Nomes-do-Pai. Rio de Janeiro: Jorge Zahar, 2005, pp. 9-53 e LACAN, Jacques. Função e campo da fala e da linguagem em psicanálise. In: Escritos. Rio de Janeiro: Jorge Zahar, 1998, pp. 238-324), ao que parece que a experiência humana é, mais que um campo de condutas guiadas apenas por imagens ordenadoras (Imaginário) e por estruturas sociossimbólicas (Simbólico) que visam a garantir e a assegurar identidades, mas também uma força disruptiva cujo nome é Real, aqui não entendido basicamente como um horizonte de experiências concretas acessíveis à consciência imediata, mas dizendo respeito a um campo de experiências subjetivas que não podem ser adequadamente simbolizadas ou colonizadas por imagens fantasmáticas. E o nome, enfim, dado por Lacan ao modo de acesso ao Real é 
Novos Estudos Jurídicos

forma, parece perder força não apenas alguma transepocalidade do direito penal como qualquer ontologização da pena como fenômeno essencial ao convívio comum.

Não obstante a diferenciação entre o fundamento da pena, vértice no qual há a inflexão sobre os porquês que a justificam, e a sua finalidade, horizonte dos juízos do para quê, o ponto de arranque que interessa examinar dá-se assumidamente, segundo Faria Costa, do pressuposto de que "a pena é uma inevitável necessidade". ${ }^{30}$ Seria descabido reconduzir o argumento já exposto em sentido contrário. Mas há espaço ainda para certas marcações. Pensar que a pena seja uma manifestação do viver comunitário, de obviedade manifesta, não conduz a intuir que seja a única maneira, muito menos deixa alheia a discussão sobre se tal figura traduz-se historicamente em avanço sob termos de humanização (supostamente o argumento dos reformistas clássicos do XVIII), ou mais propriamente uma atenta mudança na economia da punição mais preocupada com a vigilância do corpo social - não punir menos, mas punir melhor, com mais universalidade e necessidade. ${ }^{31}$

Não obstante o colorido que se empreste à concepção, o retribucionismo e suas (re)elaborações, em alguma medida, sempre fazem uso do crime como manifestação do mal, ou seja, a justiça penal lastreada na visão aristotélica da retribuição como regulador fundamental da vida social. Contudo, o professor português, para não cair numa espiral expansiva de antever o direito penal, que tem como fonte o mal inicial, repercutindo agora num outro mal que seria a pena, como faz classicamente os discursos de retribuição, atrela-se ao pensamento uníssono retomado dos ilustrados utilitaristas: a pena percebida e valorada como um bem, algo socialmente útil. ${ }^{22}$ Como se destacou antes, aí se pode ver, além do impulso reconduzido do mal contra o bem que, no mínimo desconhece o quanto isto dependerá de quem dita os seus conteúdos, o abismo da contradição entre

chamado de gozo.

30 FARIA COSTA, José de. Noções Fundamentais de Direito Penal (Fragmenta iuris poenalis) - Introdução. Coimbra: Coimbra Editora, 2007, p. 17 e FARIA COSTA, José de. Uma Ponte entre o Direito Penal e a Filosofia Penal: lugar de encontro sobre o sentido da Pena. In: Linhas de Direito Penal e de Filosofia: alguns cruzamentos reflexivos. Coimbra: Coimbra Editora, p. 210.

31 FOUCAULT, Michel. Vigiar e Punir: nascimento da prisão. 19. ed. Petrópolis: Vozes, 1987. pp. 63-85.

32 FARIA COSTA, José de. Uma Ponte entre o Direito Penal e a Filosofia Penal: lugar de encontro sobre o sentido da Pena, p. 224. 
limitar e legitimar a imposição de sofrimento (mas agora para o bem) como mecanismo de justiça, imperativo que em nada assegura contra a possibilidade do acoplamento de fundamentalismos das mais variadas espécies.

Aqui, mais do que a crença original de se expiar um mal com outro mal, como se supõe na disposição clássica retributiva, alguma crítica jurídica vem a calhar, pois afinal já demonstrara que o objetivo - agora deslocado da pena como um bem - parece incidir mais incisivamente num ato de fé. ${ }^{33}$ Se mesmo antes, a bem que se diga, de cientificidade rarefeita, fundamentava-se o retribucionismo, como dito, no dado indemonstrável do mito da liberdade na culpabilidade do autor, importa destacar que, não mais se ampara nos tons religiosos de outrora (pela expiação), mas sob um respaldo laico, canalizando o poder de punir neutramente sobre uma entidade historicamente localizada que é o Estado, acreditando por resolvidas (ou atribuindo pouco importância) a certas questões já recorrentes no debate político, principalmente, sobre as noções e os interesses conflitantes assimilados pela composição das regras estatais alçadas como interesse público.

Assim, a pena, longe de ser condição de reposição, de repristinação de tal relação primeva de "cuidado-de-perigo", representa exatamente seu contrário: apresenta-se como o desdobramento falido daquela relação ética rompida. Descompasso assumido no instante em que o cuidar do outro foi perdido, porque engolido pela mesma lógica que ambicionava protegê-lo. Dar sentido a este bem, ainda que de "uma forma consistente e poderosa" - como assaz impõem as mais terríveis justificações, pois exatamente por serem racionalmente fortes que podem abandonar seu razoável e sê-la exatamente por força da posição que previamente ocupava - estaria mais próximo de uma claudicante indiferença ética (para além de uma condição axiológica) quanto às historicidades concretas, condição da própria substância real do pensamento que, no tocante à pena, apenas descura a acumulação de catástrofes no horizonte do progresso penal.

33 Cf. ROXIN, Claus. Derecho Penal - Parte Geral. Tomo I (Fundamientos. La Estructura de la Teoría del Delito). Madrid: Civitas, 1997, pp. 81-85. 


\subsection{O NEOKANTISMO E A PENA COMO RAZÃO ESPIRITUAL}

Nas lições de Faria Costa, não obstante, mais específico ainda é seu horizonte de fundamentação da pena. Segundo ele, a fundamentação da pena não deve ser diluída em conjecturas de expiação, reprovação ou reconciliação pura e simplesmente, muito menos contíguo a um dialético "direito à pena" de viés hegeliano, em que apenas um estado racional teria o poder de subtrair do castigo seu componente de vingança. Afasta-se de Hegel, em que só nas mãos do estado racional (reflexo do infinito da razão do espírito absoluto) a pena perderia sua irracionalidade e passaria a ser ética: o delito como negação do direito cancelado por outra negação violenta, agora afirmada como pena. ${ }^{34}$

Seu sentido renovado de retribuição é empreendido desde Kant, não propriamente como uma pura manifestação do seu "desencarnado imperativo categórico", mas embebido "numa manifestação espiritual racionalmente fundada" mais perto do "sentir comum". ${ }^{35}$ Fundamentação ou legitimação que, também transcendental - mesmo ressalvado não coincidir com perversas formas de vingança, nem com uma mera percepção de senso comum -, não deixa de assentar a necessidade de imposição da pena, agora não mais, como na raiz kantiana, atrelada à preservação do estado civil, mas depreendida desde um "suposto dado onto-antropológico". Tal condição, todavia, como frisado, assume a nociva confusão entre a Proibição em sentido amplo com o produto do domínio o qual pretende o direito penal como representante deste interdito primeiro. Vez mais: se a condição existencial da convivência humana é traçada desde a Lei (o Mito fundador da Normass), reduzi-la, desmetaforizá-la ou coisificá-la em detrimento da construção da lei penal é pôr a ciência do direito penal numa posição de "suposto-saber" inabalável e, sobretudo, concedida desde a função primordial dada à punição.

34 Noção de crime como negatividade que implica a sua mesma negação expressa como pena, quer dizer, violência contra uma violência, trazida e tornada clássica na referência da sua Grundlinien der Philosophie der Rechts: "O princípio conceitual de que toda a violência destrói a si mesma possui a sua real manifestação no fato de uma violência se anular com outra violência. É assim que se torna jurídica, de maneira não só relativa, quando se dão tais condições, mas necessária, quando é aquela segunda violência que suprime a primeira. (...) Como evento que é, a violação do direito enquanto direito possui, sem dúvida, uma existência positiva exterior, mas contém a negação. A manifestação desta negatividade é a negação desta violação que entra por sua vez na existência real; a realidade do direito reside na sua necessidade ao reconciliar-se ela consigo mesma mediante a supressão da violação do direito." HEGEL, G. W. F. Princípios da Filosofia do Direito, pp. 84 e 87.

35 FARIA COSTA, José de. Uma Ponte entre o Direito Penal e a Filosofia Penal: lugar de encontro sobre o sentido da Pena, pp. 233-234.

36 Cf. GAUER, Ruth M. Chittó. A Fundação da Norma: para além da racionalidade histórica. Porto Alegre: EDIPUCRS, 2009. 
O imperativo ético se modifica, mas nem tanto para demover sua plataforma. Pode-se antes ver com mais rigor a teoria kantiana da pena. ${ }^{37}$ Importa dizer diretamente, contudo, que não raro sem uma enorme margem de erro, a concepção kantiana da pena é enquadrada sob o rótulo de teoria absoluta pela razão de, supostamente, a pena (ou a lei penal, aqui dá no mesmo) ser, para o autor alemão, um imperativo categórico. O imperativo categórico para Kant seria aquele que representa uma ação por si mesma, sem referência a nenhum outro fim, como objetivamente necessária, concebida, pois, a moral autonomamente, regida pela própria consciência. Dirá o texto da segunda das três críticas: "Age de modo que a máxima de tua vontade possa valer-te sempre como princípio de uma legislação universal", a qual, em realidade constitui, para o filósofo de Königsberg, a "Lei Fundamental da Razão Pura Prática" ${ }^{38}$. O mesmo já antecipava em 1785, três anos antes da segunda investigação:

o imperativo categórico é portanto só um único, que é este: 'Age apenas segundo uma máxima tal que possas ao mesmo tempo querer que ela se torne lei universal'. (...) Uma vez que a universalidade da lei, segundo a qual certos efeitos se produzem, constitui aquilo a que se chama propriamente 'natureza' no sentido mais lato da palavra (quanto à forma), quer dizer a realidade das coisas, enquanto é determinada por leis universais, o imperativo universal do dever poderia também exprimir-se assim: 'Age como se a máxima da tua ação se devesse tornar, pela tua vontade, em lei universal da natureza'. ${ }^{39}$

O imperativo categórico, assim, seria aquilo que representa uma ação por si mesma, sem referência a nenhum outro fim, como objetivamente necessária. Desta forma, superficialmente, a pena seria não um meio, mas um fim em si, dando-se a entender que a função punitiva não poderia estar em busca de qualquer objetivo ou finalidade. Equívoco de enorme relevo ecoado longamente. Obviamente que o universo kantiano concedia uma função à punição, do contrário seria irracional ou dogmático. Todo o arcabouço kantiano, fartamente estudado ao longo de décadas, tem por eixo a avaliação do ser humano como fim em si mesmo, daí, sim, o imperativo ético, proibindo moralmente que o ser humano fosse posto como

37 Sobre o criticismo penal, ZAFFARONI, Eugenio Raúl. Tratado de Derecho Penal - Parte General II. Buenos Aires: EDIAR, 1988, pp. 143-162.

38 KANT, Emmanuel. Crítica da Razão Prática. São Paulo: Ícone, 2005, p. 32

39 KANT, Immanuel. Fundamentação da Metafísica dos Costumes. Lisboa: Edições 70, 2005, p. 59. 
Novos Estudos Jurídicos

simples meio. Para a concepção de uma moral autônoma, regida pela própria consciência, seria necessário pressupor a autodeterminação. Daí que se deduz a outra formulação do imperativo categórico, e o imperativo prático será o seguinte: "Age de tal maneira que uses a humanidade, tanto na tua pessoa como na pessoa de qualquer outro, sempre e simultaneamente como fim e nunca simplesmente como meio" 40 . Estaria afastada a concessão de, via pena, buscar-se, por exemplo, a intimidação dos demais indivíduos. Por isso dirá que, "a pena judicial (...) não pode nunca servir simplesmente como meio para fomentar outro bem, seja para o delinquente mesmo seja para a sociedade civil, mas sim que há de se impor-se a ele somente 'porque delinquiu'." ${ }_{41}$

Como se pode verificar, segundo Zaffaroni, Batista, Alagia e Slokar, Kant deu "à pena o caráter de um meio que garantisse o próprio imperativo categórico: quis demonstrar que, sem a pena, a garantia do ser humano como fim em si mesmo acaba imediatamente." Encontrou, assim, a medida da pena no talião, proibindo qualquer amparo em dados empíricos (não lhe convinha, por ser inteiramente dedutiva sua teoria, lançar mão de qualquer casuísmo). Explicando de outro modo, para Kant, a pena seria um dever do estado civil para a sua sustentação/ manutenção (e apenas aqui o imperativo existe e é assegurado), para que não imperasse o estado de natureza (guerra ou caos) e a correlata mediatização do ser humano:

daí a necessidade da pena, que não mediatizaria o ser humano porque justamente era a única garantia de seu tratamento como humano (...), longe de ser uma teoria absoluta por concebê-la como fim em si mesmo, é a mais radical das teorias de defesa social, de vez que a vingança talional é a condição imediata do estado civil. ${ }^{42}$

Em suma, a pena jamais fora vista por ele como um imperativo categórico, um fim em si, pela pura razão da sua automática aplicação em alguém porque delinquiu. Era, sim, um meio para a garantia do imperativo categórico, respaldo, para ele, por um lado, de que o homem não seria senão um fim em si mesmo e, consequentemente, resguardando-se o Estado Civil. Tendo isto como bem

$40 \quad$ KANT, Immanuel. Fundamentação da Metafísica dos Costumes, p. 69.

41 KANT, Immanuel. Metafísica de los Costumbres. Madrid: Tecnos, 1989, p. 166

42 ZAFFARONI, Eugenio Raúl; BATISTA, Nilo; ALAGIA, Alejandro; SLOKAR, Alejandro. Direito Penal Brasileiro. Rio de Janeiro: Revan, 2003, pp. 522-523. 
assentado, percebe-se quanto o vigor neokantiano de Faria Costa pôde conservar o que ali há de essencial na necessidade da pena, mesmo que o sentido do seu neorretribucionismo ofereça novas baterias discursivas.

Talvez não fosse necessário - tamanho o manancial de críticas desde sempre realizadas aos ideários retribucionistas nos seus mais detalhados matizes e com maior contundência ainda noutros locais ${ }^{43}$ - frisar o quanto se observa de recondução de uma defesa social direta ou indiretamente nestes discursos, mesmo que numa versão mais limitada de legitimação do poder punitivo. Entretanto, cabe ver algumas de suas reconfigurações, principalmente neste novo fôlego neokantiano dado pelo professor português.

O pensamento penal contemporâneo advindo da retribuição (principalmente desde a falência e o problema da ilimitação da prevenção especial) parece ter conquistado espaço nos anos 60/70 deste século, não que antes a ideia de retribuição como limite à coerção estatal (que do contrário seria absurdamente ilimitada e destruidora da seguridade jurídica) não tenha sido posta, por exemplo, por Carrara na sua polêmica com Röder. ${ }^{44} \mathrm{O}$ enfoque neorretribucionista ganha força no movimento, como ressalta Garland45, que se aproveita da crise do correcionalismo em matéria penal que se abateu sobre o modelo welfarista moderno para deslocar a ênfase agora para o "justo merecimento", como se viu, a superioridade moral de castigos proporcionais que mirassem o passado bem representada tal filosofia retribucionista do castigo como fim em si mesmo como já anteriormente examinado em Andrew Von Hirsch. Afora tais questões, está fora de qualquer discussão que há profunda necessidade de impor limites à prevenção especial ressocializadora, todavia tal segurança jurídica não pode se chamar retribuição (castigo, reparação, expiação ou qualquer outro significante deste léxico). Aqui a segurança ambicionada dá-se muito menos por um conceito abstrato e idealmente concebido de "retribuição" (sempre à disposição da devolução de um mal) que por uma realidade socialmente construída.

43 Por todos e, sumamente, pela potência da bibliografia trazida, ver ZAFFARONI, Eugenio Raúl. Tratado de Derecho Penal - Parte General II, pp. 83-85.

44 CARRARA, Francesco. Programma del Corso di Diritto Criminale. Dettato dal Professore Francesco Carrara. Lucca: Tip. Canovetti, 1863, pp. 281-285 (§§ 646-651).

45 GARLAND, David. La Cultura del Control: crimen y orden social en la sociedad contemporánea. Traducción de Máximo Sozzo. Barcelona: Gedisa, 2005, pp. 107-136. 
A saber, a renovação do pensamento penal kantiano, tanto vista desde a Escola de Marburgo ou pela Escola de Baden, apunha o conhecimento não como captação do objeto, mas como criação do mesmo. Assinalando idealismos mais profundos que o próprio Kant, a Escola de Marburgo, na esteira da "razão pura", inclinou-se para a metodologia e lógica como refúgios seguros da certeza do conhecimento (no campo jurídico tão bem representado por Kelsen). Enquanto ali houve a negação do realismo em prol de um "metodologismo", muito mais importante para o pensamento jurídico-penal foi a "Escola do Sudoeste" da Alemanha em Baden, donde se pode antever a postura axiológica desta vertente, inspirada em Dilthey, e mais afeita à "razão prática". Destaque especial para Max Ernst Mayer e Gustav Radbruch, sem esquecer que, mais tarde, a feição mais bem-acabada para o direito penal neokantiano esteve em Edmund Mezger. ${ }^{46}$ Numa tal "filosofia dos valores" (em que eles não são, mas valem), o que importa é o próprio sentimento ao valor ali envolvido, ou seja, uma consciência normativa vinculada a um dever ser. Assim, nesta crítica geral dos valores universais, o "ser" depende e é criado pelo "dever ser". Poder-se-ia, desde sempre, questionar como há valores que valem, mas não são, e ao mesmo tempo determinam o que é? Para esta postura, noutros termos, a referência aos valores é que porá ordem na caótica realidade. E se também as valorações são historicamente condicionadas, não tarda muito, nesta renúncia metafísica, a entrada em cena do positivismo jurídico. ${ }^{47}$

Como estes matizes parecem conjurar, mesmo se a invasão da realidade, em sua tensão máxima, pudesse ser neutralizada discursivamente, se se por algum dogma iluminado dado de maneira implícita por ilusão - a vertigem da legitimidade da pena seja por retribuição ou qualquer sentido -, houvesse algo capaz de blindar assepticamente a torrente de violências naturalizadas, ainda assim, há mortes ${ }^{48}$. Inarredável ética deslegitimante do poder punitivo a qual a magnitude de qualquer pensamento penal deverá se acomodar ou se incomodar, noutro sentido, existência em decisão política permanente de salvar vidas humanas e diminuir a violência política. ${ }^{49}$

46 Sobre a filosofia jurídica neokantiana, ver RECASENS SICHES, Luis. Panorama del Pensamiento Jurídico en el Siglo XX. Primer Tomo. Mexico: Editorial Porrua, 1963, p. 223 ss.

47 ZAFFARONI, Eugenio Raúl. Tratado de Derecho Penal - Parte General II, pp. 306-312.

48 E nem se precisa lançar mão de uma maior análise sobre a operacionalidade real dos sistemas penais para se atentar para o genocídio em ato que se abate sobre estas experiências agregadoras de mais morte, exercidas sob uma violência sem paralelo. Para tanto, ver ZAFFARONI, Eugenio Raúl. Em busca das penas perdidas: a perda de legitimidade do sistema penal. Rio de Janeiro: Revan, 1991, pp. 123-125.

49 AMARAL, Augusto Jobim do. Criminologia como desconstrução - Talvez. In: Revista de Derecho Penal y Criminología, Año VII, Nº 09, octubre 2017, pp. 249-260. 
Diante disso, então como haveria de se pensar o direito penal como um ordenamento de $\operatorname{paz}^{50}$, se exatamente veicula a dobra à violência sobre si que pretensamente quer afastar? Que espécie de paz é esta - mesmo que concebida unicamente sob alguma especificidade normativa - fundada num poder de punir e de impor dor ao outro, que carrega como instrumento da sua paz redentora a espada da pena? Seria alguma paz de cemitérios?

Alguma eticidade do direito penal apenas poderia ter espaço como consequência da imposição de ser instrumento jurídico para a contenção e a redução (não pela anulação da percepção) do estado de polícia presente em toda perspectiva de estado de direito, devendo saber que o direito penal não regula o poder punitivo - e ao tentar fazê-lo, seja de forma minimamente necessária, reproduz mais violência, acobertada pela legitimidade da pena -, pois, transbordando seu infame narcisismo, retroalimenta a pulsão de violência contida em si. Exigência ética, se assim se entender, que poderá limitadamente conter, dentro da sua construção discursiva, o sempre transbordante poder de punir propenso ao aniquilamento dos valores elementares da vida comunitária. Exercitar teórica e constantemente que aquilo que é (violência punitiva), a condição histórica construída pela punição juridicamente justificada não deve ser e operar na urgência de deixar de ser (a pena) no menor tempo possível.

\section{CONSIDERAÇÕES FINAIS}

Qualquer crítica pontualmente feita aqui sempre necessária ao horizonte da ciência do direito penal, precisamente, desde as reverberações neorretribucionistas em Von Hirsh e Faria Costa, guardadas as diferenças - àquele dando novo fôlego aos discursos de prevenção via retribuição e este repaginando o idealismo kantiano desde uma estrutura antropológica acaba por nivelar o "interdito" à normal penal e à punição - ao fundo acaba por ter certa ressonância comum: densificar, de fato, ecos de um discurso penal libertário, diante de ecos que pretendem ter o direito penal como expressão de "uma ordem de liberdade". 
A esta altura da história, os engodos prestados supostamente sob os auspícios da "liberdade" já estão rançosos e não podem mais ficar impávidos. Sobre eles, assombra a inarredável e perturbadora denúncia da fragilidade em se concebê-la classicamente desde os inequívocos espaços individuais, humanos como mônadas conscientes em que a liberdade de um acaba quando a do outro inicia. Condição esta que ignora a existência comum e apenas encerra uma ordem sufocantemente transcendental, ignorando liberdades radicalmente reais que em qualquer contexto bem poderiam não existir ou nem puderam chegar a existir. Oblitera-se, assim, qualquer sentido de alteridade e, vez mais, por alguma razão jurídico-penal, suporta-se a naturalização da violência frente à socialidade humana.

\section{REFERÊNCIAS}

AMARAL, Augusto Jobim do. Criminologia como desconstrução - Talvez. In: Revista de Derecho Penal y Criminología, Año VII, Nº 09, octubre 2017, pp. 249-260.

AMELUNG, Knut. El Concepto "Bien Jurídico" en la Teoría de la Protección de Biens Jurídicos. In: HEFENDEHL, Roland. La Teoría del Bien Jurídico. ¿Fundamento y Legitimación del Derecho Penal o Juego Abalorios Dogmático? Madrid: Marcial Pons, 2007.

CARRARA, Francesco. Programma del Corso di Diritto Criminale. Dettato dal Professore Francesco Carrara. Lucca: Tip. Canovetti, 1863.

DARDOT, Pierre; LAVAL, Christian. A Nova Razão do Mundo: ensaio sobre a sociedade neoliberal. São Paulo: Boitempo, 2016.

ENRIQUEZ, Eugène. Da Horda ao Estado: Psicanálise do vínculo social. Rio de Janeiro: Jorge Zahar, 1990.

FARIA COSTA, José de. Noções Fundamentais de Direito Penal (Fragmenta iuris poenalis) Introdução. Coimbra: Coimbra Editora, 2007.

FARIA COSTA, José de. $\mathbf{O}$ perigo em direito penal. Coimbra: Coimbra Editora, 2000.

FARIA COSTA, José de. Uma Ponte entre o Direito Penal e a Filosofia Penal: lugar de encontro sobre o sentido da Pena. In: Linhas de Direito Penal e de Filosofia: alguns cruzamentos reflexivos. Coimbra: Coimbra Editora.

FOUCAULT, Michel. História da Sexualidade III: o cuidado de si. 8. ed. Rio de Janeiro: Graal, 1985.

FOUCAULT, Michel. Vigiar e Punir: nascimento da prisão. 19. ed. Petrópolis: Vozes, 1987. 
FREUD, Sigmund. La Interpretación de los Sueños. In: Obras Completas. Tomos I. Buenos Aires: El Ateneo. 2005.

FREUD, Sigmund. Totem y Tabu. In: Obras Completas. Tomo II. Buenos Aires: El Ateneo, 2005. GARLAND, David. La Cultura del Control: crimen y orden social en la sociedad contemporánea. Traducción de Máximo Sozzo. Barcelona: Gedisa, 2005.

GAUER, Ruth M. Chittó. A Fundação da Norma: para além da racionalidade histórica. Porto Alegre: EDIPUCRS, 2009.

HEGEL, G. W. F. Princípios da Filosofia do Direito. São Paulo: Martins Fontes, 1997.

HIRSCH, Andrew von. Censurar y Castigar. Madrid: Trotta, 1998.

HIRSCH, Andrew von. Doing Justice: the choice of punishments. New York: Hill \& Wang, 1976.

HIRSCH, Andrew von. Past or Future Crimes: deservedness and dangerousness in the sentencing criminals. New Brunswick: Rutgers University Press, 1987.

JAKOBS, Gunther. Sociedad, Norma, Persona: en una teoría de un derecho penal funcional. Bogotá: Universidad Externado de Colombia, 1998.

KANT, Emmanuel. Crítica da Razão Prática. São Paulo: Ícone, 2005.

KANT, Immanuel. Fundamentação da Metafísica dos Costumes. Lisboa: Edições 70, 2005. KANT, Immanuel. Metafísica de los Costumbres. Madrid: Tecnos, 1989.

LACAN, Jacques. Função e campo da fala e da linguagem em psicanálise. In: Escritos. Rio de Janeiro: Jorge Zahar, 1998.

LACAN, Jacques. O Simbólico, o imaginário e o real. In: Nomes-do-Pai. Rio de Janeiro: Jorge Zahar, 2005.

LESCH, Heiko H. La Función de la Pena. Madrid: Dykinson, 1999.

RECASENS SICHES, Luis. Panorama del Pensamiento Jurídico en el Siglo XX. Primer Tomo. Mexico: Editorial Porrua, 1963.

ROXIN, Claus. Derecho Penal - Parte Geral. Tomo I (Fundamientos. La Estructura de la Teoria del Delito). Madrid: Civitas, 1997.

ROXIN, Claus. Política Criminal e Sistema Jurídico-Penal. Rio de Janeiro: Renovar, 2002. STRAWSON, Peter. F. Freedom and Resentment. In: Freedom and Resentment and Other Essays. London: Routledge, 2008. 
ROSA, Alexandre Morais da; AMARAL, Augusto Jobim do. Cultura da Punição: a ostentação do horror. 4. ed. Florianópolis: Empório do Direito, 2017.

TAYLOR, Ian; WALTON, Paul; YOUNG, Jock. The new criminology: for a social theory of deviance. London: Routledge \& Kegan Paul Ltda., 1973.

WASSERSTROM, Richard A. Punishment. In: Philosophy and Social Issues: five studies. South Bend: Notre Dame University Press, 1980.

ZAFFARONI, Eugenio Raúl. A Questão Criminal. Tradução Sérgio Lamarão. 1.ed. Rio de Janeiro: Revan, 2013.

ZAFFARONI, Eugenio Raúl. Em busca das penas perdidas: a perda de legitimidade do sistema penal. Rio de Janeiro: Revan, 1991.

ZAFFARONI, Eugenio Raúl. Tratado de Derecho Penal - Parte General II. Buenos Aires: EDIAR, 1988.

ZAFFARONI, Eugenio Raúl; BATISTA, Nilo; ALAGIA, Alejandro; SLOKAR, Alejandro. Direito Penal Brasileiro. Rio de Janeiro: Revan, 2003. 